\title{
Influence of team rating on running performance in elite Gaelic football
}

\author{
Shane Mangan \\ Technological University Dublin, shane.mangan@tudublin.ie \\ Shane Malone \\ Technological University Dublin, Shane.Malone@TUDublin.ie \\ Martin Ryan \\ Technological University Dublin
}

See next page for additional authors

Follow this and additional works at: https://arrow.tudublin.ie/ittsciart

Part of the Medicine and Health Sciences Commons

\section{Recommended Citation}

Mangan S, Malone S, Ryan M, Mc Gahan J, Warne J, Martin D, O'Neill C, Burns C, Collins K. Influence of Team Rating on Running Performance in Elite Gaelic Football. J Strength Cond Res. 2018 Sep;32(9):2584-2591. doi: 10.1519/JSC.0000000000002316. PMID: 29120985.

This Article is brought to you for free and open access by the School of Science and Computing at ARROW@TU Dublin. It has been accepted for inclusion in Articles by an authorized administrator of ARROW@TU Dublin. For more information, please contact arrow.admin@tudublin.ie, aisling.coyne@tudublin.ie, gerard.connolly@tudublin.ie.

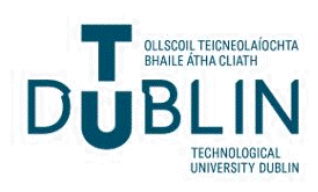




\section{Authors}

Shane Mangan, Shane Malone, Martin Ryan, Jason McGahan, Joe Warne, Denise Martin, Cian O'Neill, Con Burns, and Kieran Collins 


\title{
Influence of Team Rating on RunNing Performance in Elite Gaelic Football
}

\author{
Shane Mangan, ${ }^{1}$ Shane Malone, ${ }^{1}$ Martin Ryan, ${ }^{1}$ Jason Mc Gahan, ${ }^{2}$ Joe Warne,,${ }^{1,3}$ \\ Denise Martin, ${ }^{4}$ Cian O’Neill, ${ }^{2}$ Con Burns, ${ }^{2}$ and Kieran Collins ${ }^{1}$ \\ ${ }^{1}$ Department of Science, Gaelic Sports Research Center, Institute of Technology Tallaght, Tallaght, Ireland; ${ }^{2}$ Department of \\ Sport, Leisure and Childhood Studies, Cork Institute of Technology, Cork, Ireland; ${ }^{3}$ Setanta College, Thurles Chamber of \\ Commerce, Thurles, Tipperary, Ireland; and ${ }^{4}$ Department of Business, Institute of Technology, Dublin, Ireland
}

\begin{abstract}
Mangan, S, Malone, S, Ryan, M, Mc Gahan, J, Warne, J, Martin, D, O'Neill, C, Burns, C, and Collins, K. Influence of team rating on running performance in elite Gaelic football. J Strength Cond Res 32(9): 2584-2591, 2017-It is currently unknown how team rating influences running performance in Gaelic football. Global positioning system technologies were used to quantify match-running performance within 5 elite Gaelic football teams over a period of 5 years (2012-2016). In total 780 player data sets were collected over 95 matches. Running performance variables included total distance, high-speed distance $\left(\geq 17 \mathrm{~km} \cdot \mathrm{h}^{-1}\right)$, and the percentage of high-speed distance. Team ratings were determined objectively using the Elo rating system for Gaelic football. Reference team rating had trivial effects on total distance $\left(p=0.011\right.$, partial $\eta^{2}=$ 0.008 ) and high-speed distance $\left(p=0.011\right.$, partial $\left.\eta^{2}=0.008\right)$. Opposition team rating had small effects on total distance $(p=$ 0.005 , partial $\left.\eta^{2}=0.016\right)$ and high-speed distance $(p=0.001$, partial $\eta^{2}=0.020$ ). Top-tier teams cover greater total distances and high-speed distance than lower tier teams. Players cover considerably less total distance and high-speed distance against tier-3 and tier-4 teams. Tier-1 players ran a significantly higher percentage of distance at high speed than players who played for tier-2 teams $(p=0.020)$. The competitive advantage of top-tier Gaelic football teams is closely linked with their ability to demonstrate a higher physical intensity than lower tier teams.
\end{abstract}

KEY WoRDS opposition, team rating, opposition rating, contextual factors, global positioning systems

\section{INTRODUCTION}

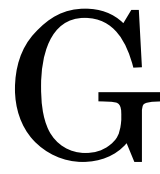

aelic football is one of the national sports of Ireland (25). Attendances at matches can surpass 82,000 people in Croke Park, the national headquarters of the Gaelic Athletic Association

Address correspondence to Shane Mangan, manganshane@gmail.com. 32(9)/2584-2591

Journal of Strength and Conditioning Research

(c) 2017 National Strength and Conditioning Association
(GAA). It is perhaps surprising that Gaelic football is an amateur sport, given these figures; however, training regimens are more akin to professional sports $(2,18,31)$. Matches are contested by 2 teams of 15 players on a pitch about $33 \%$ bigger than a soccer pitch $(130-145 \mathrm{~m}$ in width and $80-90 \mathrm{~m}$ in length) (27). The duration of a match is 70 minutes, with additional time for stoppages in play added on at the referee's discretion. Within Ireland's 32 counties, Gaelic football players play for their clubs at a subelite level. Intercounty competitions represent the elite level of Gaelic football, with teams made up of the best club players in each county (20). The 2 major competitions in which elite teams compete are the National Football League (NFL) and the All Ireland Football Championship (AIFC) (22). The NFL is contested between 32 teams, whereas the AIFC is contested between 33 teams including representative teams from New York and London.

Gaelic football is similar to Australian football and soccer in terms of relative match-play distances covered by players (19). Gaelic football players will run between 8,160-9,222 m in a competitive match $(9,20,21)$. Because it is an intermittent sport, players will run between 1,695-1,731 $\mathrm{m}$ at high speed $\left(\geq 17 \mathrm{~km} \cdot \mathrm{h}^{-1}\right)(9,20,21)$. Playing position influences the running performance of Gaelic football players, with half-backs, midfielders, and half-forwards covering greater distances than full-backs and full-forwards (20). In addition, total distance covered and high-speed distance are significantly reduced in quarters 2, 3, and 4 in comparison with the first quarter (19). This decrement in performance is most often linked with conditioning, metabolic factors, and fatigue (19).

It has been suggested that in addition to fatigue and positional differences, other contextual factors may influence running performance in Gaelic football matches $(19,23)$. One potential factor is team rating (19). Previous research in rugby league (13) identified that players covered a greater volume of high-speed $\left(\geq 18 \mathrm{~km} \cdot \mathrm{h}^{-1}\right)$ running when competing against lower ranked teams than against higher ranked teams. This finding is in contrast to observations in soccer $(15,26)$ where players covered greater distances at high speed $(\geq 14, \geq 19.1$ $\mathrm{km} \cdot \mathrm{h}^{-1}$ ) when playing against higher rated teams. Similarly, Australian football players cover greater relative distances 
when playing against higher rated opposition (29). The lack of agreement in these results could be explained by the different game structures in Australian football, rugby league, and soccer (34). In soccer, lower rated teams have been observed to cover more distance at high intensity than top rated teams $(3,30)$. Gaelic football running demands increase throughout the season, potentially because of better teams progressing to the latter stages of the AIFC (24). However, the true influence of team rating on running performance in Gaelic football is not yet known (19). This information would be of interest to sport scientists and strength and conditioning coaches who monitor running performance. To produce relevant analyses, practitioners should be aware of all the factors involved.

Unlike in most sports (32), there are no official team ratings in Gaelic football. This has meant that in the past it has been difficult to classify Gaelic football teams (6). More recently, a system previously used to rate chess players and soccer teams has been adapted for Gaelic football (22). The Elo rating system for Gaelic football considers previous results, home advantage, opposition rating, match importance, and score margin when calculating a team's rating. The system has $73 \%$ accuracy for predicting victory (22). Therefore, the aim of the current study was to use the Elo rating system for Gaelic football to determine the extent to which total distance and high-speed distance are influenced by reference team rating and by opposition team rating in elite Gaelic football match play. The research will also investigate what influence team rating and opposition team rating have on high-speed distance per match quarter.

\section{Methods}

\section{Experimental Approach to the Problem}

The current research took an observational approach to determine the extent to which total distance and high-speed distance are influenced by team rating in elite Gaelic football match play. Gaelic football players were monitored in competitive matches $(n=95)$ using global positioning system (GPS) technology. Only instances where a player completed the full game were used for final analysis $(n=780)$. Data collection points were determined by the schedule of matches and the success of the teams involved. Data were collected from competitive matches in the NFL $(n=469)$ and the AIFC $(n=311)$ over a 5 -year period $(2012, n=65$; 2013, $n=90$; 2014, $n=131 ; 2015, n=217$; and 2016, $n=$ 277). Team ratings were noted for both teams at the time of any given match (22). Teams were separated into 4 tiers based on their Elo rating; tier 1 ( $\geq 1,728$ Elo points), tier 2 (1,511-1,727 Elo points), tier 3 (1,348-1,510 Elo points), and tier 4 ( $\leq 1,347$ Elo points) (22). For discursive purposes, the teams who were involved in this study are referred to as the reference team. The teams who they faced are referred to as the opposition. At the time of data collection, all the reference teams were in the top 2 tiers. This meant that no GPS data were available from tier 3 and tier 4 teams. However, teams faced by the reference teams came from all 4 tiers.

\section{Subjects}

All data were anonymized before data analysis and were processed with accordance to the Declaration of Helsinki. Elite adult (mean $\pm S D$ : age; $26.2 \pm 2.8$ years [age range: 18 years and older]) male Gaelic football players $(n=93)$ participated in this study over a period of 5 years (2012-2016). Anthropometric data were not collected for all participants; so, it is not reported here. The players came from 5 intercounty Gaelic football teams, who had agreed to partake in this research. Two teams participated in the study for 1 season, 2 teams participated for 2 seasons, and 1 team participated for 3 seasons. Players were included on the basis that they were selected as an outfield (full-back, half-back, midfield, half-forward, and full-forward) player for their intercounty team and they provided written informed consent. Before the recruitment of subjects, ethical approval was received from the Institute of Technology Tallaght. Subjects were provided information on the study and were told that they could withdraw at any stage throughout the research.

\section{Procedures}

The validity and reliability of the GPS devices used in this study (4 Hz; VX Sport, Lower Hutt, New Zealand) have been previously established $(5,17)$. The coefficient of variation $(\mathrm{CV})$ for the devices are less than $5 \%$ for average speed, maximum speed, total distance, and low-speed distance; however, high-speed distance has a CV of $8 \pm 2.5 \%$ (95\% confidence interval $[\mathrm{CI}]$ ) (17). Each player was equipped with a harness containing the GPS device before each game. The protective harness was worn around the chest with the GPS device positioned between the shoulder blades in an upright position. The devices were turned on at least $15 \mathrm{mi}-$ nutes before each match to establish a satellite link (16).

Individual player data were extracted from the devices after each game using the VX Sport software (Firmware 4.01.2.0; VX Sport View) on a Windows-based laptop. All the data were time-stamped, which meant that match files could be trimmed to ensure that only the time a player spent on the pitch was retained, omitting periods such as the warm-up and half-time. Match data were divided into 4 time quarters using the VX Sport software. All data were saved into a custom spreadsheet (Excel; Microsoft, Redmond, USA). Total distance (meter), high-speed distance $\left(\geq 17 \mathrm{~km} \cdot \mathrm{h}^{-1} ; \mathrm{m}\right)$, and minutes spent on the pitch were noted for all players. Percentage high-speed distance was calculated by dividing the total distance ran at high speed $\left(\geq 17 \mathrm{~km} \cdot \mathrm{h}^{-1} ; \mathrm{m}\right)$ by the total distance (meter). This was done to ensure that high-speed distance was relative to the total distance that each player ran in a match. All running performance data were anonymized before analysis as per institution guidelines.

\section{Statistical Analyses}

Statistical analysis was performed in SPSS for Mac (Statistical Package for the Social Sciences data analysis software version 16.0; SPSS, Inc., Chicago, IL, USA). Before the commencement of statistical analysis, assumptions of 
TABLE 1. The effect of team rating and opposition team rating on running performance. ${ }^{*}$

\begin{tabular}{|c|c|c|c|c|c|c|c|}
\hline \multirow[b]{2}{*}{ Performance indicator } & \multicolumn{2}{|c|}{ Reference team quality } & \multicolumn{4}{|c|}{ Opposition team quality } & \multirow[b]{2}{*}{$\begin{array}{l}\text { Average } \\
(n=780)\end{array}$} \\
\hline & $\begin{array}{c}\text { Tier } 1 \\
(n=620)\end{array}$ & $\begin{array}{c}\text { Tier } 2 \\
(n=160)\end{array}$ & $\begin{array}{c}\text { Tier } 1 \\
(n=457)\end{array}$ & $\begin{array}{c}\text { Tier } 2 \\
(n=118)\end{array}$ & $\begin{array}{c}\text { Tier } 3 \\
(n=154)\end{array}$ & Tier $4(n=51)$ & \\
\hline Total distance $(\mathrm{m})$ & $\begin{array}{l}8,725 \pm 2,015 \\
(8,395-8,829)\end{array}$ & $\begin{array}{c}8,251 \pm 1,575 \\
(7,746-8,431) \dagger\end{array}$ & $\begin{array}{r}8,709 \pm 2,054 \\
(8,447-8,972)\end{array}$ & $\begin{array}{c}8,697 \pm 2,015 \\
(8,274-9,121)\end{array}$ & $\begin{array}{l}8,193 \pm 1,421 \\
(7,882-8,505)\end{array}$ & $\begin{array}{l}7,800 \pm 1,665 \\
(7,242-8,359) \pm\end{array}$ & $\begin{array}{r}8,628 \pm 1,942 \\
(8,492-8,765)\end{array}$ \\
\hline High-speed distance (m) & $\begin{array}{l}1,606 \pm 650 \\
(1,518-1,658)\end{array}$ & $\begin{array}{l}1,472 \pm 531 \\
(1,305-1,527) \dagger\end{array}$ & $\begin{array}{l}1,615 \pm 670 \\
(1,530-1,700)\end{array}$ & $\begin{array}{l}1,651 \pm 601 \\
(1,513-1,788)\end{array}$ & $\begin{array}{l}1,451 \pm 492 \\
(1,350-1,552)\end{array}$ & $\begin{array}{l}1,289 \pm 581 \\
(1,109-1,471) \pm \S\end{array}$ & $\begin{array}{l}1,578 \pm 630 \\
(1,534-1,622)\end{array}$ \\
\hline $\begin{array}{l}\text { Percentage high-speed } \\
\text { distance (\%) }\end{array}$ & $\begin{array}{l}17.88 \pm 4.24 \\
(17.49-18.43)\end{array}$ & $\begin{array}{c}17.38 \pm 4.08 \\
(16.17-17.66) \dagger\end{array}$ & $\begin{array}{l}18.07 \pm 4.25 \\
(17.50-18.64)\end{array}$ & $\begin{array}{c}18.57 \pm 3.68 \\
(17.65-19.49)\end{array}$ & $\begin{array}{l}17.35 \pm 3.88 \\
(16.67-18.03)\end{array}$ & $\begin{array}{l}15.75 \pm 5.38 \\
(14.54-16.96) \ddagger \S\end{array}$ & $\begin{array}{l}17.78 \pm 4.21 \\
(17.48-18.08)\end{array}$ \\
\hline $\begin{array}{l}\text { High-speed } \\
\text { distance quarter } 1(\mathrm{~m})\end{array}$ & $\begin{array}{l}434 \pm 186 \\
(407-449)\end{array}$ & $\begin{array}{c}404 \pm 178 \\
(361-426)\end{array}$ & $\begin{array}{l}435 \pm 194 \\
(418-452)\end{array}$ & $\begin{array}{l}472 \pm 166 \\
(439-505)\end{array}$ & $\begin{array}{l}392 \pm 162 \\
(363-421) \S\end{array}$ & $\begin{array}{c}369 \pm 173 \\
(319-420) \S\end{array}$ & $\begin{array}{l}428 \pm 185 \\
(400-434)\end{array}$ \\
\hline $\begin{array}{l}\text { High-speed } \\
\text { distance quarter } 2(\mathrm{~m})\end{array}$ & $\begin{array}{l}398 \pm 186 \\
(366-405)\end{array}$ & $\begin{array}{c}353 \pm 136 \\
(307-370)\end{array}$ & $\begin{array}{r}402 \pm 192 \\
(386-418)\end{array}$ & $\begin{array}{l}427 \pm 168 \\
(395-458)\end{array}$ & $\begin{array}{c}342 \pm 131 \\
(314-369) \pm \S\end{array}$ & $\begin{array}{l}326 \pm 150 \\
(278-374) \pm \S\end{array}$ & $\begin{array}{l}389 \pm 178 \\
(358-391)\end{array}$ \\
\hline $\begin{array}{l}\text { High-speed } \\
\text { distance quarter } 3(\mathrm{~m})\end{array}$ & $\begin{array}{l}402 \pm 186 \\
(382-423)\end{array}$ & $\begin{array}{r}363 \pm 169 \\
(302-367)\end{array}$ & $\begin{array}{l}404 \pm 193 \\
(387-420)\end{array}$ & $\begin{array}{l}415 \pm 172 \\
(382-448)\end{array}$ & $\begin{array}{c}372 \pm 154 \\
(343-400)\end{array}$ & $\begin{array}{l}332 \pm 188 \\
(282-382) \ddagger \S\end{array}$ & $\begin{array}{r}394 \pm 184 \\
(363-398)\end{array}$ \\
\hline $\begin{array}{l}\text { High-speed } \\
\text { distance quarter } 4(\mathrm{~m})\end{array}$ & $\begin{array}{l}371 \pm 168 \\
(352-388)\end{array}$ & $\begin{array}{c}352 \pm 145 \\
(320-378)\end{array}$ & $\begin{array}{l}365 \pm 170 \\
(350-380)\end{array}$ & $\begin{array}{l}415 \pm 166 \\
(386-444) \ddagger\end{array}$ & $\begin{array}{l}356 \pm 137 \\
(330-381) \S\end{array}$ & $\begin{array}{c}317 \pm 145 \\
(273-362) \S\end{array}$ & $\begin{array}{l}367 \pm 163 \\
(348-378)\end{array}$ \\
\hline
\end{tabular}

*Values are mean $\pm S D$. Significant difference is set at 0.05 . $95 \%$ confidence intervals $(\mathrm{Cls})$ are presented in brackets.

†Reference team quality: Significantly different from tier-1 teams $(p \leq 0.020)$.

Opposition team quality: Significantly different from tier- 1 teams $(p \leq 0.036)$

§Opposition team quality: Significantly different from tier-2 teams $(p \leq 0.033)$. 
normality were assessed. The data passed assumptions of normality; however, the data for total distance and highspeed distance did not pass Levene's test of equality of error variances. Likewise, the data for high-speed distance per quarter did not pass Box's test of equality of covariance matrices. Because the data set was very large, we continued with the current statistical model (14). Data are presented as mean, $S D$, and $95 \%$ CIs. Statistical significance was accepted at $\alpha \leq 0.05$. A 2-way analysis of variance (ANOVA) was used to examine the interaction between team rating and opposition rating on total distance (meter) and high-speed distance $\left(\geq 17 \mathrm{~km} \cdot \mathrm{h}^{-1} ; \mathrm{m}\right)$ and percentage high-speed distance. A 3-way repeated-measures mixed ANOVA was used to analyze the interaction between team rating and opposition team rating with the high-speed distance covered across quarters $(1,2,3$, and 4$)$. Where a significant 3 -way interaction was observed, a series of 1-way and 2-way ANOVAs were performed. Tukey's post hoc analyses were used to determine within group differences. The partial eta-squared $\left(\eta^{2}\right)$ value was used as a measure of effect size (ES) (8). Effect size benchmarks specific to partial eta-squared (7) were used to divide effects into small (0.0099-0.0587), medium $(0.0588-0.1378)$, and large $(>0.1379)(28)$.

\section{Results}

\section{Total Distance}

Statistical results for total distance can be observed in Table 1 and Figure 1. There was no significant interaction between team rating and opposition team rating for total distance $(p=0.215)$. However, both team rating $(p=0.011$, partial $\left.\eta^{2}=0.008\right)$ and opposition team rating $(p=0.005$, partial $\left.\eta^{2}=0.016\right)$ had trivial-to-small effects individually on total distance. Tier-1 players were observed to run a significantly greater distance than tier-2 players $\left(p=0.011, \eta^{2}=0.008\right)$. Players ran a significantly greater distance when they played against tier-1 teams as opposed to when they played against tier-4 teams $(p=0.024)$. There were no other significant differences in total distance when playing against tier-2 and tier-3 teams.

\section{High-Speed Distance}

Statistical results for high-speed distance can be observed in Table 1 and Figure 2. There was no significant interaction between team rating and opposition team rating for highspeed distance $(p=0.148)$. Team rating $(p=0.011$, partial $\left.\eta^{2}=0.008\right)$ and opposition team rating $(p=0.001$, partial $\left.\eta^{2}=0.020\right)$ had trivial-to-small effects on high-speed distance. Tier-1 players covered a greater amount of highspeed distance than tier-2 players $\left(p=0.011\right.$, partial $\eta^{2}=$ 0.008 ). Players ran significantly more high-speed distance against tier-1 teams $(p=0.009)$ and tier- 2 teams $(p=$ 0.011) than they did against tier-4 teams (Figure 2). There was no difference in high-speed distance between other tiers for opposition team rating.

A 2-way interaction was observed between team rating and opposition team rating for percentage of high-speed distance $(p=0.020)$ with a small effect (partial $\eta^{2}=0.013$ ). Players who played for tier- 1 teams ran a significantly higher percentage of distance at high-speed than players who played for tier-2 teams $(p=0.020)$. A greater percentage of high-speed distance was run against tier-1 $(p=0.004)$ and tier-2 $(p=0.002)$ teams than against tier- 4 teams. There were no other significant differences in high-speed distance for opposition team rating.

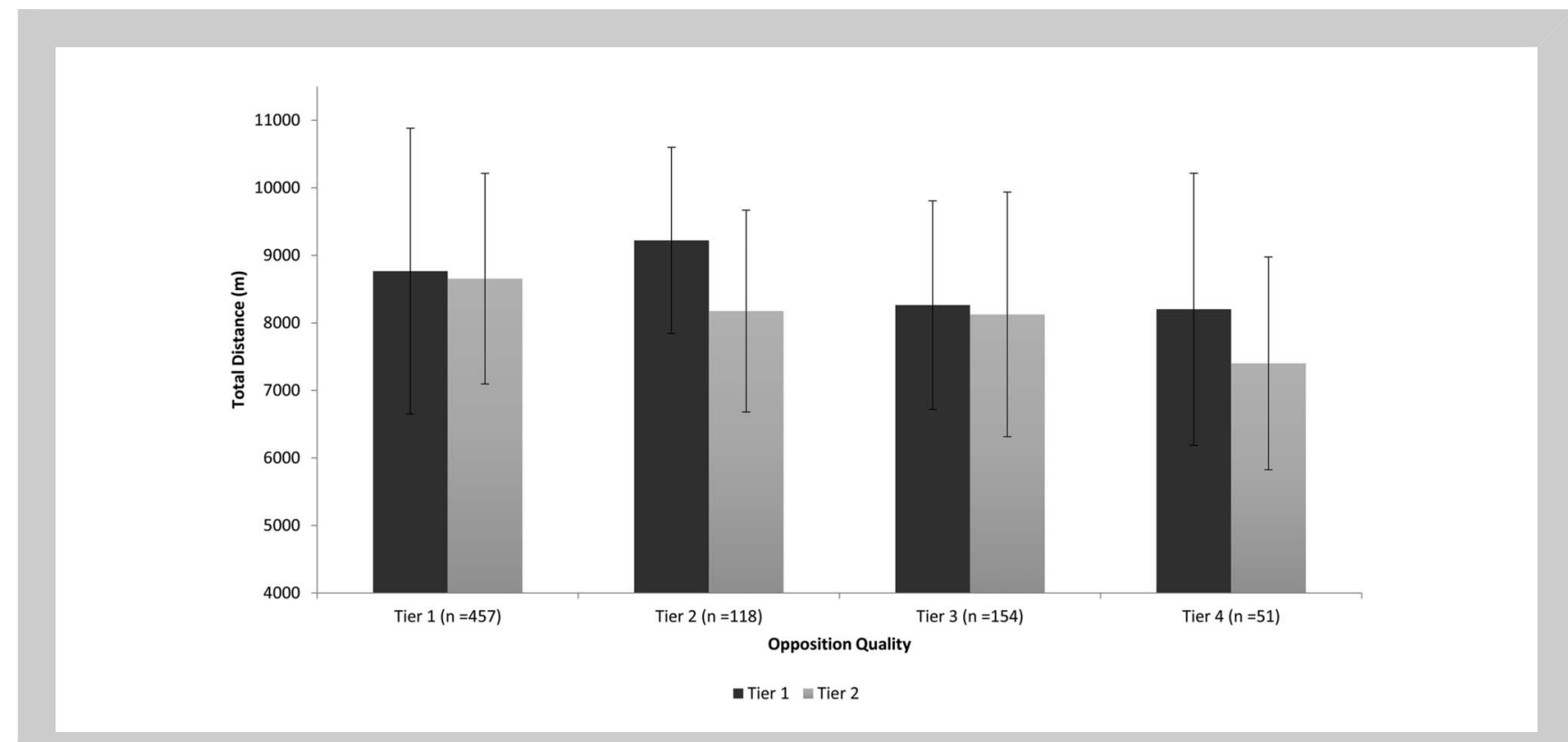

Figure 1. The effect of team rating and opposition team rating on total distance (meter). 


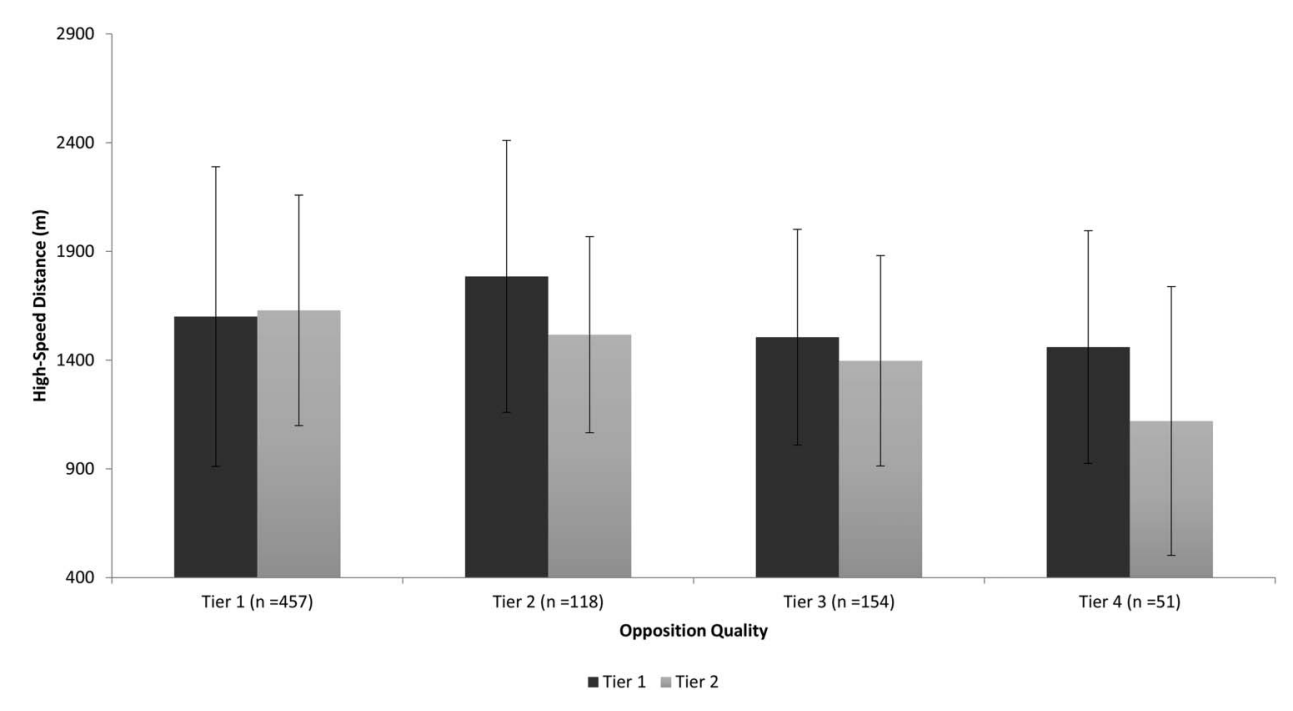

Figure 2. The effect of team rating and opposition team rating on total distance high-speed distance $\left(\geq 17 \mathrm{~km} \cdot \mathrm{h}^{-1} ; \mathrm{m}\right)$.

A 3-way interaction effect was observed between team rating, opposition team rating, and match quarter on highspeed distance $(p \leq 0.001)$ with a small effect evident (partial $\eta^{2}=0.019$ ). To better understand this 3-way interaction, separate 2-way analyses were performed. A 2-way analysis revealed that there was no significant interaction between team rating and match quarter on high-speed distance $\left(p=0.148\right.$, partial $\left.\eta^{2}=0.002\right)$. However, opposition team rating had a small effect on high-speed distance per match quarter $\left(p=0.003\right.$, partial $\left.\eta^{2}=0.011\right)$. The effects of opposition team rating on high-speed distance per match quarter are presented in Figure 3. There was no significant interaction between team rating and opposition team rating for high-speed distance in quarters 1,2 , and 4 . In the third quarter, however, tier-1 players ran significantly more distance at high-speed than tier- 2 players $\left(p=0.014, \eta^{2}=\right.$ $0.008)$, whereas a significantly lower amount of high-speed distance was run in games against tier-4 teams in comparison

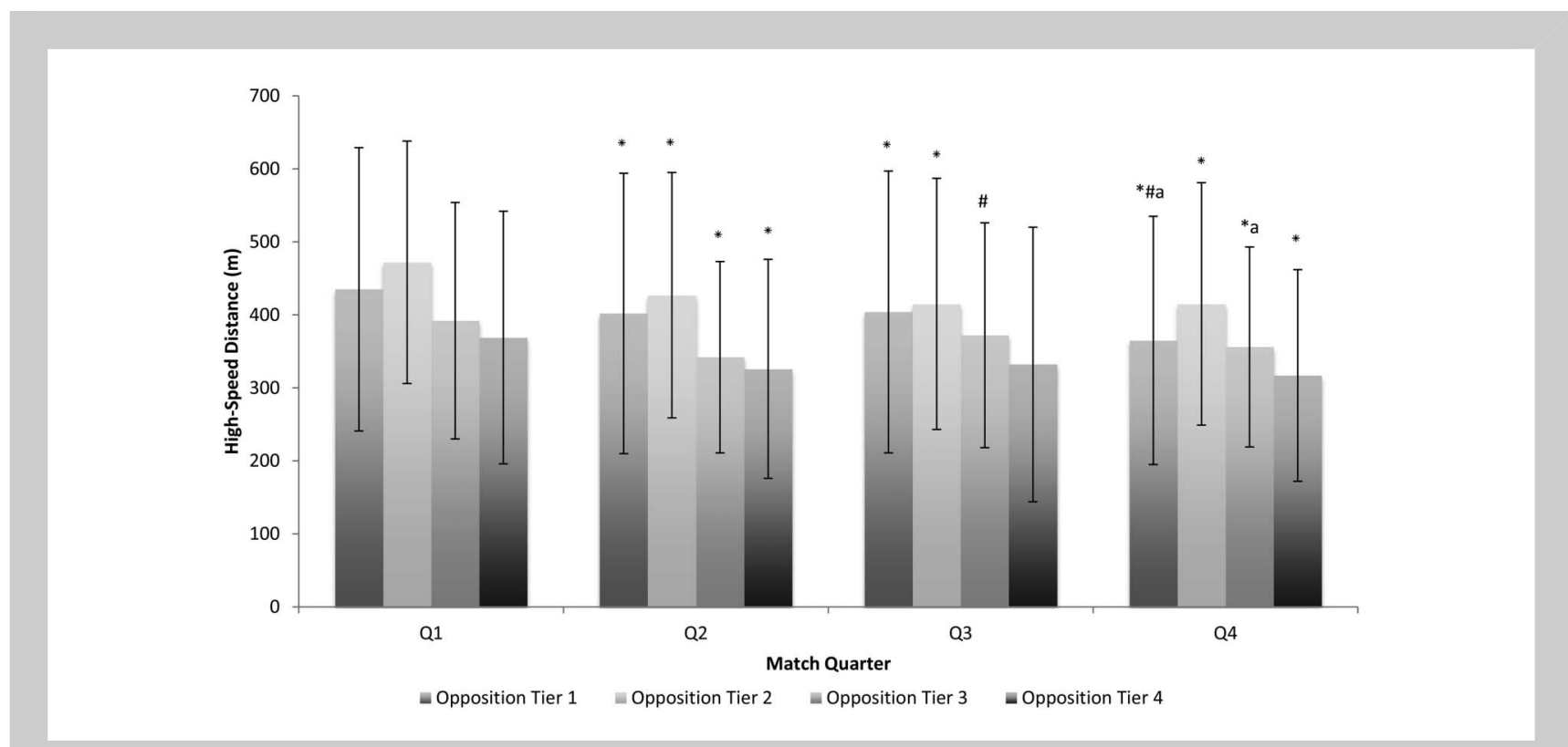

Figure 3. The effect of opposition rating on high-speed distance $\left(\geq 17 \mathrm{~km} \cdot \mathrm{h}^{-1} ; \mathrm{m}\right)$ per match quarter. 
with games against tier-1 $(p=0.047)$ and tier-2 $(p=0.042)$ teams. The 2-way analyses suggest that the 3 -way interaction is caused by a strong interaction between opposition rating and match quarter and less so by the reference team rating (Figure 3).

A significant decrement in high-speed distance was evident from the first quarter to the last quarter, regardless of opposition team rating $\left(p \leq 0.001, \eta^{2}=0.028\right)$. A $16 \%$ drop-off in high-speed running was observed from the first quarter to the fourth quarter when playing against tier-1 teams. The drop-off was less pronounced when playing tier-2 (12\%), tier-3 (9\%), and tier-4 teams (14\%). The dropoff in high-speed running from the first to the last quarter was higher for the reference teams in tier $1(14 \%)$ than in tier $2(11 \%)$.

\section{Discussion}

The current study is the first to examine the effects of team rating on running performance in Gaelic football. The major findings of this research are that both team rating and opposition team rating have small effects on running performance in Gaelic football matches. Players representing tier-1 teams were observed to run a greater total distance and undertake a greater high-speed distance than those who played for tier-2 teams. Players ran a greater total distance and a greater amount of high-speed distance when playing against top-tier teams as opposed to playing against bottomtier teams. Running distances were greatest when playing against tier-2 teams. These findings suggest that the competitive advantage of top-tier Gaelic football teams is firmly associated with their ability to display a higher physical intensity than lower rated teams.

The findings of the current research are similar to that in soccer (26), with players covering greater total distance and greater high-speed distance against top-tier teams than they did against bottom-tier teams. This difference could be attributed to a number of factors. Playing against higher rated opposition has been shown to promote greater movement synchronization between teammates and elicit greater physical demands for professional soccer players (12). This can be related to the amount of possession that a team has (4) and the fact that teams need to have a greater defensive structure when playing against top-level opposition (12). Previously, in Gaelic football, it has been shown that when top teams play other top teams, they have fewer possessions in the opposition's half of the pitch than when they play against bottom teams (6). This is likely to affect both the attacking and defensive structure of the team, resulting in an increase in physical performance when playing against better opposition. Top-tier teams are perhaps more likely to commit more players forward in an attack than lower tier teams because of their superior fitness levels (1) and greater confidence in their defensive ability should they lose possession. Top-tier teams cover a greater percentage of distance at high-speed than tier-2 teams, demonstrating their ability to play the game at a higher intensity. Likewise, when playing against tier-4 teams, players cover a lower percentage of distance at high speed than when they face tier-1 and tier2 opposition.

Another potential explanation for these differences is that top-tier teams might tend to pace themselves more when playing against lower rated opposition (10). It has been suggested that intermittent team sport players alter their behavior (physical exertion) during matches based on both prematch contexts (e.g., previous experience in similar circumstances, fitness levels, and match importance) and physiological alterations during the game $(10,11)$. In the case of this study, the lower distances covered against lower rated teams may be influenced by the prematch bias of the reference team players. Given that top teams have more attacking possessions against lower rated teams (6), players on top-tier teams may subconsciously refrain from exerting themselves fully as they know that they will get a greater number of chances to attack.

The highest total distances and high-speed distances were recorded when tier-1 teams played against tier-2 teams. If top teams have a similar amount of attacks when they play other top teams (6), the increase in the number of attacks when they play tier-2 teams could be a reason for the increase in running performance. One can speculate from this that teams might cover greater distances when attacking in comparison with when they defend. However, when tier1 teams play tier- 3 and tier- 4 teams, both total distance and high-speed distance are reduced. This is possibly due to pacing (10). Another potential explanation is that highly skilled players demonstrate greater decision-making skills than those who are less skilled (35). Players with greater decision-making skills react quicker to external stimuli, which mean they are more efficient in their movements (33). When playing against tier-4 opposition, tier-1 teams cover a considerably greater amount of total distance and high-speed distance than tier-2 teams. This suggests that top-tier teams are less likely to ease off when playing against bottom-tier teams, perhaps an indication of the competition for starting places in tier- 1 teams.

A decrement in high-speed running was evident from the first quarter to the fourth quarter, irrespective of team rating, which is consistent with previous observations (19). As with the overall high-speed distance, players were observed to cover a greater amount of high-speed distance in each of the 4 quarters when playing against tier-2 teams. The greatest drop-offs in high-speed running from the first to the fourth quarter were observed for the reference teams in tier 1 and when playing against tier- 1 opposition. The level of intensity in the first 3 quarters in games between top teams is most likely the cause of the decrease in the final quarter (10).

A major limitation of this study is that in most cases, running performance data were not available for both teams in a match. Commercial agreements mean that county teams are often limited to using particular models of GPS device. 
In the current study, only 3 matches took place between teams who participated in this research. As a consequence of the level of quality of the teams who participated in this research, data were only collected from tier- 1 and tier-2 teams. This restricted the comparisons that could be made for team rating and running performance. Over the course of the study, 1 of the teams went from a tier- 2 team to a tier- 1 team because of their success. Because the Elo rating points and Elo tier were noted at the time of each game, this change was reflected in the results. If teams were not successful over the course of data collection, a series of bad results may have seen them go down to a lower tier; however, this situation did not arise. Again, because of the level of teams that participated, a far greater number of data points were collected when teams were playing against tier-1 teams $(n=457)$ as opposed to playing against tier- 4 teams $(n$ $=51$ ). Further research is required to examine running performance in lower tier teams. Further limitations of this research were that elements such as technical performance, match scheduling, playing experience, participant anthropometrics, dietary intake, and weather conditions were not considered in the analyses.

\section{Practical Applications}

The current study is the first to report that running performance is influenced by team rating in Gaelic football. Both the reference team rating and opposition team rating were found to cause changes in running performance in Gaelic football players. The present data indicates that Gaelic football players should be physically prepared so that they can cover greater total distances and greater distance at high-speed when competing against higher rated opposition. These findings may influence the timing of substitutions based on the quality of opposition faced. Opposition team rating had stronger effects on running performance than the reference team rating. Toptier teams cover greater distances than lower tier teams, whereas players cover considerably less total distance and high-speed distance against tier- 3 and tier- 4 teams. This information is useful for training where teams could potentially adjust the physical demands of drills/training matches by selecting teams of different quality. Teams may also use this information to periodize their training differently based on the quality of opposition that they will face in the NFL because they will know their opponents 9 months in advance. Postmatch analysis of physical performance should incorporate contextual factors such as team rating and opposition team rating. Future research should examine running performance with respect to technical game event data.

\section{REFERENCES}

1. Arnason, A, Sigurdsson, SB, Gudmundsson, A, Holme, I, Engebretsen, L, and Bahr, R. Physical fitness, injuries, and team performance in soccer. Med Sci Sport Exerc 36: 278-285, 2004.
2. Beasley, KJ. Nutrition and Gaelic football: Review, recommendations, and future considerations. Int J Sport Nutr Exerc Metab 25: 1-13, 2015.

3. Bradley, PS, Archer, DT, Hogg, B, Schuth, G, Bush, M, Carling, C, and Barnes, C. Tier-specific evolution of match performance characteristics in the English Premier League: It's getting tougher at the top. J Sports Sci 414: 1-8, 2015.

4. Bradley, PS and Noakes, TD. Match running performance fluctuations in elite soccer: Indicative of fatigue, pacing or situational influences? J Sports Sci 31: 1627-1638, 2013.

5. Buchheit, M, Allen, A, Poon, TK, Modonutti, M, Gregson, W, and Di Salvo, V. Integrating different tracking systems in football: Multiple camera semi-automatic system, local position measurement and GPS technologies. J Sports Sci 32: 1844-1857, 2014.

6. Carroll, R. Team performance indicators in Gaelic football and opposition effects. Int J Perform Anal Sport 13: 703-715, 2013.

7. Cohen, J. Statistical Power Analysis for the Behavioural Sciences. New York, NY: Academic Press, 1969.

8. Cohen, J. Statistical power analysis for the behavioral sciences. Stat Power Anal Behav Sci 2: 567, 1988.

9. Collins, K, Solan, B, and Doran, DA. A preliminary investigation into high-intensity activity during elite Gaelic football. $J$ Sport Ther 1: 10, 2013.

10. Coutts, AJ, Quinn, J, Hocking, J, Castagna, C, and Rampinini, E. Match running performance in elite Australian rules football. $J \mathrm{Sci}$ Med Sport 13: 543-548, 2010.

11. Edwards, AM and Noakes, TD. Dehydration: Cause of fatigue or sign of pacing in elite soccer? Sport Med 39: 1-13, 2009.

12. Folgado, H, Duarte, R, Fernandes, O, and Sampaio, J. Competing with lower level opponents decreases intra-team movement synchronization and time-motion demands during pre-season soccer matches. PLoS One 9, 2014.

13. Gabbett, T. Influence of the opposing team on the physical demands of elite rugby league match play. J Strength Cond Res 27: 1629-1635, 2013.

14. Jaccard, J. Interaction Effects in Factorial Analysis of Variance. Thousand Oaks, CA: Sage Publications, 1998. Available at: https://books.google.ie/ books?hl=en\&lr=\&id=liAHMTUoqjMC\&oi=fnd\&pg=PR5\&dq=jaccard +1998\&ots=FrWQt22h1F\&sig=TGzV_2zQ3_w8XVUjSmkZlr7O-Hs\& redir_esc $=\mathrm{y} \# \mathrm{v}=$ onepage\& $\mathrm{q}=$ jaccard1998\&f=false.

15. Lago, C, Casais, L, Domínguez, E, and Rey, E. The effect of match location, quality of opposition and match status on work rate in elite soccer. Eur J Hum Mov 23: 107-121, 2010.

16. Maddison, R and Ni Mhurchu, C. Global positioning system: A new opportunity in physical activity measurement. Int J Behav Nutr Phys Act 6: 73, 2009.

17. Malone, S, Doran, D, Collins, K, Morton, J, and McRobert, A. Accuracy and reliability of VXsport global positioning system in intermittent activity. In: Proceedings of the 19th Annual Congress of the European College of Sport Science, Amsterdam, the Netherlands, 2014.

18. Malone, S, Roe, M, Doran, DA, Gabbett, TJ, and Collins, KD. Aerobic fitness and playing experience protect against spikes in workload: The role of the acute: Chronic workload ratio on injury risk in elite Gaelic football. Int J Sports Physiol Perform 32: 1-25, 2016.

19. Malone, S, Solan, B, and Collins, K. The running performance profile of elite Gaelic football match-play. J Strength Cond Res 31: 1-25, 2017.

20. Malone, S, Solan, B, Collins, K, and Doran, D. Positional match running performance of elite Gaelic football. $J$ Strength Cond Res 30: 2292-2298, 2016.

21. Malone, S, Solan, B, Collins, K, and Doran, D. The metabolic power and energetic demands of elite Gaelic football match play. J Sport Med Phys Fit 57: 1-20, 2016.

22. Mangan, $\mathrm{S}$ and Collins, K. A rating system for Gaelic football teams: Factors that influence success. Int J Comput Sci Sport 15: 78-90, 2016. 
23. Mangan, S, Malone, S, Ryan, M, McGahan, J, O’Neill, C, Burns, C, Warne, J, Martin, D, and Collins, K. The influence of match outcome on running performance in elite Gaelic football. Sci Med Footb 3, 2017. Epub ahead of print.

24. Mangan, S, Ryan, M, Shovlin, A, McGahan, J, Malone, S, O’Neill, C, Burns, C, and Collins, K. Seasonal changes in Gaelic football match-play running performance. $J$ Strength Cond Res, 2017. Epub ahead of print.

25. McIntyre, MC and Hall, M. Physiological profile in relation to playing position of elite college Gaelic footballers. BrJ Sports Med 39: 264-266, 2005.

26. Rampinini, E, Coutts, AJ, Castagna, C, Sassi, R, and Impellizzeri, FM. Variation in top level soccer match performance. Int J Sports Med 28: 1018-1024, 2007.

27. Reilly, T and Collins, K. Science and the Gaelic sports: Gaelic football and hurling. Eur J Sport Sci 8: 231-240, 2008.

28. Richardson, J. Eta squared and partial eta squared as measures of effect size in educational research. Educ Res Rev 6: 135-147, 2011.

29. Ryan, S, Coutts, AJ, Hocking, J, and Kempton, T. Factors affecting match running performance in professional Australian football. Int $J$ Sports Physiol Perform 9: 1-19, 2017.
30. Di Salvo, V, Gregson, W, Atkinson, G, Tordoff, P, and Drust, B. Analysis of high intensity activity in premier league soccer. Int J Sports Med 30: 205-212, 2009.

31. Shovlin, A, Roe, M, Malone, S, and Collins, K. The positional anthropometric and performance profile of elite Gaelic football players. J Strength Cond Res 1, 2017.

32. Stefani, R. The methodology of officially recognized international sports rating systems. J Quant Anal Sport 7: 10, 2011.

33. Vaeyens, R, Lenoir, M, Philippaerts, RM, and Williams, AM. Mechanisms underpinning successful decision making in skilled youth soccer players: An analysis of visual search behaviors. $J$ Mot Behav 39: 395-408, 2007.

34. Varley, MC, Gabbett, T, and Aughey, RJ. Activity profiles of professional soccer, rugby league and Australian football match play. J Sports Sci 32: 1858-1866, 2014.

35. Williams, AM, Ward, P, Knowles, JM, and Smeeton, NJ. Anticipation skill in a real-world task: Measurement, training, and transfer in tennis. J Exp Psychol Appl 8: 259-270, 2002. 